\title{
Surveying prenatal attachment in fathers: the Italian adaptation of the Paternal Antenatal Attachment Scale (PAAS-IT)
}

\section{Anna M. Della Vedova \& Roberto Burro}

To cite this article: Anna M. Della Vedova \& Roberto Burro (2017): Surveying prenatal attachment in fathers: the Italian adaptation of the Paternal Antenatal Attachment Scale (PAAS-IT), Journal of Reproductive and Infant Psychology, DOI: 10.1080/02646838.2017.1371284

To link to this article: http://dx.doi.org/10.1080/02646838.2017.1371284

曲 Published online: 11 Sep 2017.

Submit your article to this journal $\widetilde{ }$

Џ Article views: 18

Q View related articles $\square$

View Crossmark data ¿ 


\title{
Surveying prenatal attachment in fathers: the Italian adaptation of the Paternal Antenatal Attachment Scale (PAAS- IT)
}

\author{
Anna M. Della Vedova ${ }^{a}$ and Roberto Burro ${ }^{b}$ \\ ${ }^{a}$ Clinical and Experimental Sciences Department, University of Brescia, Brescia, Italy; ${ }^{b}$ Department of Human \\ Sciences, University of Verona, Verona, Italy.
}

\begin{abstract}
Objective: This study focuses on the process of the father's bonding with the fetus and aims to assess the psychometric properties of the Italian translation of the Paternal Antenatal Attachment Scale (PAAS). Background: The construct of prenatal attachment has been created to systematically investigate the nature of the particular bond that develops in the minds of parents expecting a child. Paternal attachment to the unborn child has not been well explored until now, despite its undoubted importance. The PAAS is a 16-item questionnaire evaluating paternal thoughts, feelings, attitudes and emotions towards the fetus validated with Australian fathers.

Methods: This is a cross-sectional study. A forward-backward translation was used to obtain the PAAS Italian version (PAAS-IT). A sample of 165 Italian fathers completed the PAAS-IT, the 20-Toronto Alexithymia Scale and a sociodemographic questionnaire also investigating the father's attitudes towards the fetus. The reliability and construct validity of the PAAS-IT were evaluated. A Principal Component Analysis (PCA) and a Confirmatory Factor Analysis (CFA) using Structural Equation Modelling (SEM) were conducted.

Results: The PAAS-IT psychometric characteristics were adequate. The PCA yielded a two-dimensional model explaining $34 \%$ of the variance. The CFA acknowledges the truthfulness of this model. The items loading on the two factors did not exactly match that found in the original PAAS, suggesting the influence of specific cultural features.

Conclusions: The PAAS-IT is a reliable and valid instrument to use in Italian clinical settings to investigate the development of the paternal attachment towards the unborn child.
\end{abstract}

\section{ARTICLE HISTORY}

Received 10 February 2017

Accepted 23 July 2017

\section{KEYWORDS}

Antenatal attachment; paternal; alexithymia; assessment; SEM

\section{Introduction}

The relevance of early relationships for the psychological development of the individual is well established. More than a half century of clinical and research evidence supports the extraordinary influence of the early interactions between the newborn and its caregivers, substantiating the intersubjective nature of the mind's development (Sameroff, 1999). However, the relationship between parents and child has its roots before the birth of a baby 
and may be affected by many environmental and personal factors influencing the psychological process of transition to parenthood. The prenatal origin of the parent-child relationship was initially recognised by authors from a psychoanalytical domain (Bibring, 1959; Cramer \& Palacio-Espasa, 1993; Deutsch, 1945; Soulé, 1982; Stern, 1995; Winnicott, 1958), highlighting the complexity of psychological processes of parenthood and the relevance of thoughts, feelings, fantasies and anticipatory images of the baby developing in the mind of the parents during pregnancy.

Thus, the construct of 'prenatal attachment' (Condon, 1993; Cranley, 1981; Muller, 1993) has been created to systematically investigate the nature of the particular bond that develops in the minds of parents who are expecting a child. Some authors have suggested that prenatal attachment can be viewed as the precursor of the care-giving system (Bowlby, 1969; Walsh, 2010), so the purpose of studying the parent-fetus relationship is to identify determinants of sensitive, competent parenting that fosters healthy child development.

While maternal bonding with the fetus has been extensively investigated (Alhusen, 2008; Brandon, Pitts, Denton, Stringer, \& Evans, 2009; Cannella, 2005; Cataudella, Lampis, Busonera, Marino, \& Zavattini, 2016; Della Vedova, 2005, 2014; Della Vedova, Dabrassi, \& Imbasciati, 2008; Laxton-Kane \& Slade, 2002; Van den Bergh \& Simons, 2009; Yarcheski, Mahon, Yarcheski, Hanks, \& Cannella, 2009), the paternal side of prenatal attachment has been far less well explored until now (Condon, Corkindale, Boyce, \& Gamble, 2013). Two instruments have been created to assess paternal prenatal attachment: the Paternal Antenatal Attachment Scale (PAAS; Condon, 1993) developed with a sample of Australian fathers, and the Paternal Fetal Attachment (PFA; Weaver \& Cranley, 1983), obtained by adapting the maternal version of the questionnaire (MFA; Cranley, 1981).

The available literature shows that both mothers and fathers during pregnancy develop a form of affective bonding and commitment towards their unborn baby. Most of the studies confirm that maternal affective investment gradually increases during pregnancy, reaching its maximum by the third trimester, and being higher in first-time mothers. A similar trend has also been found for fathers (Condon et al., 2013; Habib \& Lancaster, 2006, 2010). Some differences between mothers and fathers have also been highlighted: there is a general agreement that fathers score lower on prenatal attachment scales compared to mothers (Condon, 1985, 1993; Ustunsoz, Guvenc, Akyuz, \& Oflaz, 2010). Righetti, Dell'Avanzo, Grigio, and Nicolini (2005) found that, unlike women's, men's antenatal attachment did not increase following the ultrasound examination. Seimyr, Sjögren, Welles-Nyström, and Nissen (2009) found that the factor structure for men of an antenatal attachment questionnaire differed from the factor structure for women, suggesting that men were more involved with the 'future baby' than with the fetus. While in women antenatal depression has been found to affect prenatal attachment (Seimyr et al., 2009), Kunkel and Doan (2003) failed to find any effect of depression level on fathers' prenatal attachment scores.

A topic of particular interest is the potential association between pre- and postnatal bonding and its impact on child development. In mothers, higher prenatal attachment has been found to enhance the quality of postnatal mother-baby interaction (Siddiqui \& Hägglöf, 2000). More recently, Condon et al. (2013), using the PAAS, found that the paternal antenatal attachment score was the most powerful predictor of the father's attachment to the infant at six and 12 months postpartum. A cohort longitudinal prospective study exploring the continuity of parental bonding from pregnancy to toddlerhood (de Cock et al., 2016) has found a moderate stability of bonding in both mothers and fathers and, in case of low 
bonding patterns, the presence of parental problems in multiple domains. These results seem to support the importance of early detection and intervention with parents who have poor prenatal attachment.

As the importance of father involvement with young children has been well documented (Ramchandani et al., 2013), the present study aims to assess the psychometric properties of the Italian translation of the PAAS (Condon, 1993), which will increase the field's knowledge about the transition to fatherhood and shed light on the development of paternal prenatal attachment.

\section{Methods}

\section{Study design}

This is a cross-sectional study aimed to develop an Italian adaptation of the PAAS (Condon, 1993) by evaluation of its reliability and construct validity. An initial Principal Component Analysis (PCA) was chosen to analyse the dimensions underpinning the scale without imposing a predefined structure on the data. The underlying hypothesis was whether the emerging structure in Italian fathers was comparable to that of Australian fathers. A subsequent Confirmatory Factor Analysis (CFA) using Structural Equation Modelling (SEM) was conducted in order to assess the fit of the previously developed dimensions. To evaluate concurrent validity, the Italian version of the PAAS was compared with the 20-Toronto Alexithymia Scale (TAS-20; Bagby, Parker, \& Taylor, 1994), which is assumed to measure one's difficulty in recognising, expressing and elaborating emotions, and with the Paternal Antenatal Attitudes towards Fetus (PAAF), an instrument which was built specifically to capture some aspects of the paternal bonding towards the unborn baby. The expectations were that the PAAS which is known to measure the emotional bonding with the fetus - would positively correlate with the PAAF and inversely correlate with the TAS-20 global scores and subscales.

\section{Participants}

Men attending public health clinics for parents and babies in a medium-sized city in northern Italy were eligible for the study if they were Italian, aged 18 or older and their partners were in the third trimester of pregnancy with a singleton pregnancy. Participants were contacted at the third-month ultrasound examination or through their partners attending antenatal classes. Considering the minimum ratio of subjects per item of 10/1 (Boyle, 1985) for undertaking factor analysis, at least 160 subjects would be required. The study was approved by the relevant Ethics Committee.

\section{Procedure}

The research was explained to women by a psychologist in the waiting room while they waited for the ultrasound examination with their partners. If the men were not present, their partners were given a written letter with information about the study to pass on to their partners. Those that agreed to participate completed the measures and a consent form at home and sent it back using a pre-paid envelope. 


\section{Measures}

Participants filled in a background questionnaire and the Italian version of the PAAS (Condon, 1993) called the PAAS-IT. In addition, the 20-Toronto Alexithymia Scale (Bagby et al., 1994) and the Paternal Antenatal Attitudes towards the Fetus (PAAF) - a brief questionnaire which was created to evaluate the father's attitudes towards his unborn child - were administrated as a measure of concurrent validity.

The PAAS was developed by Condon (1993) using unstructured interviews with expectant couples. The theoretical background for this measure is a model of adult attachment (Bretherton, 1985). A 16-item questionnaire was obtained from the original pool of 36 items assessing intensity and quality of parental emotional and behavioural experiences towards the fetus in the past two weeks. Items are rated on a five-point Likert scale ranging from 1 to 5 , with a total score range of 16-80 for the Global Attachment Score (GAS). Lower scores indicate less antenatal attachment. A two-factor structure was found using exploratory factor analysis. The two subscales are: Quality of Attachment (QA), which refers to the quality of the emotional experience (e.g. happiness/sadness), and Intensity of Attachment (IA), which refers to the time spent in attachment mode (e.g. how much time spent picturing the fetus in the imagination). In a subsequent study, C. J. Corkindale (personal communication, September, 2004) suggested that items 6 and 8 should be excluded from the subscale scores due to their low loadings on the two factors. In the original study (Condon, 1993) the instrument was administrated to 112 Australian fathers and was found to have satisfactory reliability (Cronbach's alpha .800). The mean and standard deviation of the GAS and the QA and IA subscales were, respectively: 57.0 (8.3), 38.3 (4.5), 18.7 (5.0).

\section{The PAAS-IT}

The Italian adaptation of the PAAS (Appendix 1) followed the standard translation procedure (Beaton, Bombardier, Guillemin, \& Ferraz, 2000). The PAAS was translated into Italian and then a native English translator, blind to the original version of the questionnaire, back-translated it. Then the original version and the back-translation were compared to minimise differences between them. The resultant version was also compared with a previous existing Italian version of the PAAS (Righetti et al., 2005) to achieve the final version. Finally, the Italian version (PAAS-IT) was updated to be suitable for Italian culture. A pilot group of 10 expectant fathers, recruited from the same sites as for the main study, were asked to indicate any lack of clarity or possible misunderstanding in the questions. Among them, five (50\%) suggested that item number 1 ('Over the past two weeks I have thought about, or been preoccupied with the developing baby') was ambiguous, two (20\%) indicated clearly that the part 'or been preoccupied with' should be removed, three (30\%) were satisfied with the item. Therefore, to minimise the ambiguity, the words: 'or been preoccupied with' were deleted without any other changes relating to the scoring direction. So item 1 in the PAAS-IT becomes: 'Over the past two weeks I have thought about the developing baby'.

\section{The background questionnaire}

A self-report questionnaire was devised to collect various demographic and personal history information such as: age, education, occupation, marital status, number of children, sex of the expected baby, previous experience of abortion, problem with current pregnancy. 
The 20-Toronto Alexithymia Scale (TAS-20; Bagby et al., 1994; Bressi et al., 1996)

The TAS-20 is a 20-item self-report scale assessing alexithymia. The alexithymia construct measures a person's difficulty in identifying and describing his or her emotions, and the tendency to focus attention externally, thereby minimising his/her emotional experience. Items are rated on a five-point Likert-scale from 1 to 5, with a total score range of 20-100. Lower scores indicate less alexithymia, with the cut-off score of 61 or more indicating the presence of alexithymia. It consists of three subscales named, respectively, difficulty identifying feelings (F1), difficulty describing feelings (F2), and externally oriented thinking (F3). The TAS-20 has been used in diverse populations, including women during pregnancy, with adequate psychometric properties (Della Vedova et al., 2008).

\section{The Paternal Antenatal Attitudes towards the Fetus (PAAF)}

A nine-item questionnaire was created to measure the expectant father's attitude towards his fetus and as a measure of concurrent validity for the PAAS-IT. It consists of nine items assessing the expectant father's emotional involvement with his expected baby and the different ways he interacts with his unborn baby on a six-point Likert-scale. Approximate English translations are: (1) 'How did you feel when you knew you were going to have a baby?' (2) ‘Do you believe that you have some sort of communication with the baby?' (3) ‘Do you believe that the baby is aware of your attention to him/her?' (4) 'Do you feel emotionally involved with the baby?' (5) 'Do you touch your partner's stomach to feel the baby moving?' (6) 'Do you talk to the baby?' (7) 'Do you call the baby by name?' (8) Do you sing to the baby?' (9) 'Do you touch your partner's stomach to communicate with him?' Emotional items were measured on an intensity scale (from 1 'not true at all' to 6 'very true'), interactional items were measured on a frequency scale (from 1 'never' to 6 'always'). Higher scores indicate higher involvement with the fetus, with possible scores ranging from 6 to 54 .

\section{Statistical analysis}

The psychometric properties of the Italian version of the PAAS (PAAS-IT) were investigated by evaluation of its reliability and construct validity. The PAAS-IT reliability was evaluated by estimation of Cronbach's alpha coefficient of internal consistency and by a split-half reliability analysis (Spearman-Brown coefficient). A PCA was conducted where dimensions were identified taking into account that a crucial decision in PCA is how many components/domains to extract. Best practice suggests that the Parallel Analysis (PA) is one of the more robust methods (Horn, 1965). PA is an alternative technique that compares the scree of components of the observed data with that of a random data matrix of the same size as the original. An orthogonal rotation was chosen, with Quartimax being found to provide the best solution. The clustering of items on a factor was determined using loadings of 0.3 or more. Then, the factor structure was analysed using a CFA using SEM. In order to assess the fit of the previous PCA dimensions, in agreement with Schermelleh-Engel, Moosbrugger, and Müller (2003), we have operated using absolute fit indexes that tell us how well the hypothesized model fits the sample data (e.g. standardized root mean residual; root mean square error of approximation), and incremental fit indexes that rely on comparison with a reference model to determine the amount of improvement in model fit (e.g. adjusted goodness of fit index; non-normed fit index; comparative fit index). Bartlett's test and Kaiser-Meyer-Olkin (KMO) 
measure of factorability and of sampling adequacy were calculated. To test concurrent validity a Pearson's correlation analysis was conducted between PAAS-IT and TAS-20, and between PASS-IT and the PAAF. Analysis of variance (ANOVA) was used to analyse sociodemographic, background and pregnancy-related variables with respect to PAAS-IT score. All statistical analyses were carried-out with the R-software (R Core Team, 2016; psych-package for PCA (Revelle, 2016); lavaan-package for CFA (Rosseel, 2012)).

\section{Results}

From the 208 eligible men approached to participate in the research, 42 (20.2\%) declined. Subsequently one $(0.4 \%)$ questionnaire was excluded because of missing information, leaving complete data from 165 men (79.4\% of eligible participants).

\section{Participants' characteristics}

The men's average age was 34 (range 23-49, median 33); all were in a stable relationship with the baby's mother, $74 \%$ were married and $26 \%$ cohabiting; $18.8 \%$ had a university education; $100 \%$ were employed, with the majority of occupations being: clerks (24\%), professionals (22.28\%), workers (17.14\%), artisans (13.14\%), entrepreneurs and executives $(12,02 \%)$. For 150 (90.9\%) fathers it was their first child. Mean gestational age was 31.3 weeks (range $27-39$, median 31 ). Sex of the fetus was: $48.5 \%$ female, $41.8 \%$ male and $9.7 \%$ unknown; $12.1 \%$ of fathers said that they would prefer not to know the sex of their baby before the birth. The pregnancy was wanted for $79.4 \%$ of the men, $11 \%$ of the pregnancies were 'at risk' and $14.5 \%$ of their partners had had a previous miscarriage.

\section{Psychometric characteristics of PAAS-IT, TAS-20 and PAAF}

The descriptive statistics of the PAAS-IT are displayed in Table 1. The Italian version of the PAAS showed adequate internal consistency and reliability, the Cronbach's alpha coefficient was .763 and the Spearman-Brown coefficient was .739. Calculation of skewness and kurtosis $z$ scores confirmed that the distribution was approximately normally distributed (Kim, 2013). The TAS-20 descriptive statistics were consistent with the Italian validation study (Bressi et al., 1996). Mean and standard deviation of the total scale and the subscales were, respectively: 43.13 (10.46), 11.37 (4.47), 12.93 (4.79) and 18.83 (4.79); the Cronbach's alpha coefficients were, respectively: .775, $.741, .736$ and .503 . The PAAF showed satisfactory psychometric properties, the Cronbach's alpha coefficient was .758, mean and standard deviation were 39.56 (6.54).

Table 1. Descriptive statistics of the PAAS-IT $(N=165)$ global score and subscales.

\begin{tabular}{lccc}
\hline & Mean (SD) & Range & Cronbach's alpha \\
\hline Global Attachment score & $64.01(5.70)$ & $46-76$ & .763 \\
*Fantasising about the unborn baby & $44.85(5.16)$ & $27-56$ & .756 \\
*Anticipating the real baby & $19.16(1.30)$ & $11-20$ & .491 \\
\hline
\end{tabular}

Note: PAAS-IT, Paternal Antental Attachment Scale - Italian Translation.

*Subscales derived from factor analysis in the present study. 


\section{PCA and CFA}

Bartlett's test indicated that the PAAS-IT data were suitable for factor analysis $(p<0.0001)$. The KMO measure of sampling adequacy was .750, which is considered an adequate value to conduct factor analysis. The intercorrelation matrix shows almost all coefficients are positive, with no coefficients exceeding .65 , meaning that there were no redundant item pairs. The PCA with Quartimax rotation produced a multidimensional solution explaining $62.98 \%$ of the total variance. The obtained structure is similar to the one found in the original study by Condon (1993) (Table 2). The Parallel Analysis suggests that the best number of dimensions is equal to two (Figure 1). The analysis was subsequently forced to two factors, yielding a solution explaining $34.58 \%$ of the total variance. The resultant factor structure of the PAAS-IT is summarised in Table 3. Twelve items loaded on the first factor, which accounted for $23.07 \%$ of the variance, and four items loaded on the second factor, which accounted for $11.51 \%$ of the variance. The items belonging to these factors were not exactly the same as those in the two factors originally found by Condon (1993). Thus, considering the meaning of the items loading on each one, the two factors were named, respectively: 'Fantasising about the unborn baby' and 'Anticipating the real baby'. The alpha coefficient of the first factor (Fantasising about the unborn baby) was .756 and for the second factor (Anticipating the real baby) was .491. No item elimination would improve the alpha values. Then, a CFA, which is widely applied as a method to test hypothesised factor models items/dimensions (Raimondo, 2000; Watkins, 1989) was conducted on previous data. In agreement with Schermelleh-Engel et al. (2003), Table 4 displays the main index of the model's goodness of fit to the sample's data. Generally, the variables are highly associated to the domain. Figure 2 shows the standardised structural coefficients of the 16 items. There are no significant errors linking items. The items' range values of the standardised structural coefficients are between 0.48 and 0.91. The model is deemed acceptable.

\section{Correlational analysis}

The PAAS-IT correlational analysis with the PAAF and the TAS-20 and its subscales (TAS-20 F1, TAS-20 F2, TAS-20 F3) is displayed in Table 5.

\section{Analysis of associations between PAAS-IT and fathers' variables}

The PAAS-IT was controlled for sociodemographic, background and pregnancy-related variables. No variables affected the PAAS-IT score, except for parity. First-time fathers scored significantly higher than fathers with children in the PAAS-IT global score (mean score 64.41

Table 2. Italian vs. Australian fathers sample (Condon, 1993): characteristics of the factor solution.

\begin{tabular}{|c|c|c|c|c|}
\hline \multirow[b]{2}{*}{ Components } & \multicolumn{2}{|c|}{ Italian sample solution $(N=165)$} & \multicolumn{2}{|c|}{ Australian sample solution $(N=112)$} \\
\hline & Eigen value & $\%$ of variance & Eigen value & $\%$ of variance \\
\hline 1 & 3.93 & 24.54 & 4.9 & 30.7 \\
\hline 2 & 1.60 & 10.03 & 1.9 & 11.6 \\
\hline 3 & 1.29 & 8.09 & 1.2 & 7.5 \\
\hline 4 & 1.09 & 6.93 & 1.1 & 6.6 \\
\hline 5 & 1.04 & 6.86 & 1.0 & 6.1 \\
\hline 6 & 1.0 & 6.51 & & \\
\hline
\end{tabular}




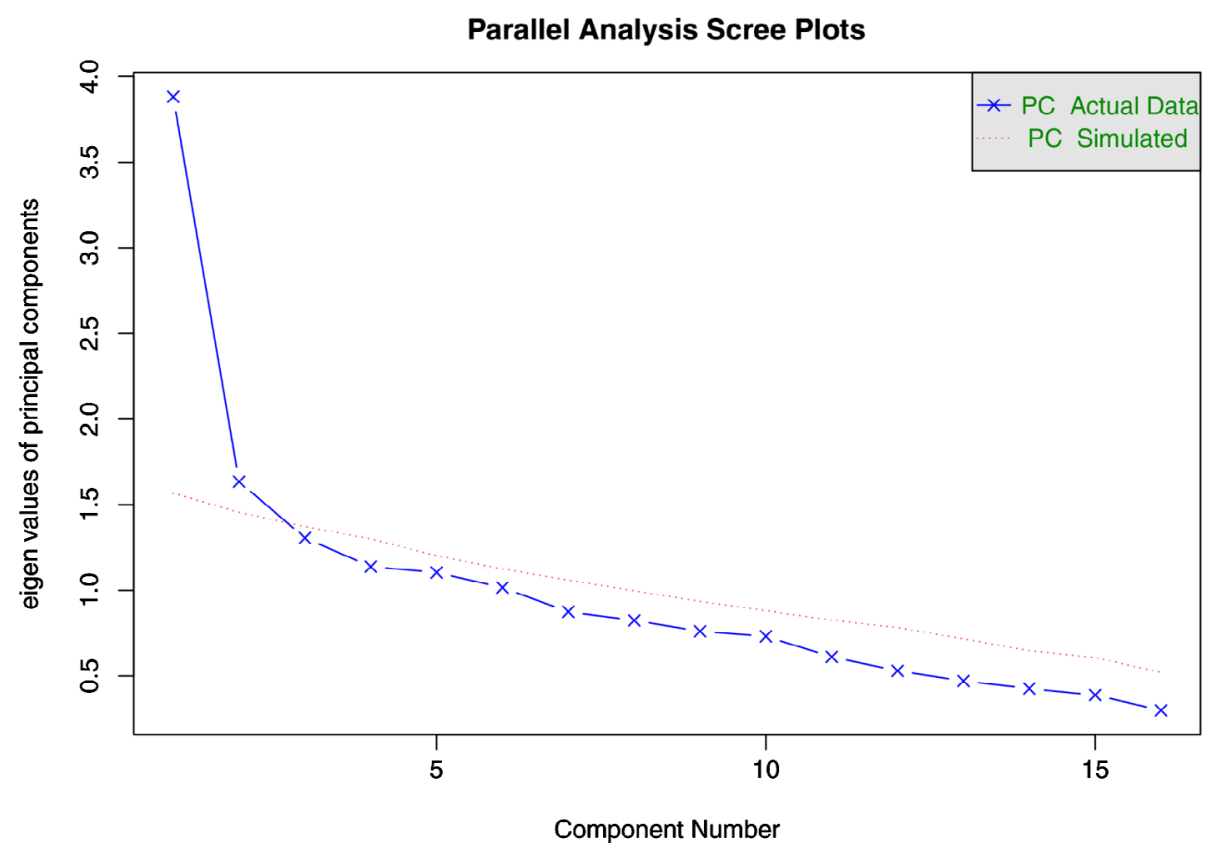

Figure 1. Above: Parallel analysis scree plot. The best domain number is where the actual data line rises above the simulated data line.

Table 3. Factor analysis: two-factor rotated solution. Method of extraction: Principal Component Analysis, Quartimax rotation.

\begin{tabular}{llc}
\hline & & \multicolumn{1}{c}{ Loadings on } \\
\cline { 3 - 3 } Item number & \multicolumn{1}{c}{ Items description* } & Factor 2 \\
\hline 1 & Frequent/infrequent thoughts of fetus & .706 \\
2 & Strong/weak feelings accompanying thoughts of fetus & .679 \\
5 & Frequent/infrequent picturing fetus in imagination & .668 \\
13 & Hold neonate immediately/late & .563 \\
11 & Feelings emotionally close to/distant from fetus & .532 \\
3 & Positive/negative feelings towards fetus & .530 \\
10 & Frequent/infrequent thoughts of future child & .479 \\
4 & Strong/weak desire to read or get information about fetus & .456 \\
15 & Frequent/infrequent palpation of fetus & .449 \\
7 & Tender/irritable feelings towards fetus & .423 \\
14 & Frequent/infrequent dreams about baby & .421 \\
6 & Fetus as a little person/thing & .366 \\
16 & Sadness/mixed feelings towards fantasised fetal loss & \\
8 & Clear/vague ideas of baby's names & \\
9 & Happy/sad feelings about fetus & \\
12 & Anticipate positive/negative first impression of baby & .666 \\
\hline
\end{tabular}

*Reverse-scored items have been recoded in the direction of positive attachment.

vs $60.00, F=8.542, p<.004$ ) and in the 'Fantasising about the unborn baby' dimension (mean score 45.24 vs $41.00, F=9.682, p<.002)$.

\section{Discussion}

The aim of the study was to investigate the psychometric properties of the Italian translation of the PAAS (PAAS-IT) and its factor structure. The response rate was satisfactory, the internal 
Table 4. Model goodness-of-fit indexes of the 16-item questionnaire.

\begin{tabular}{lc}
\hline Index & Goodness-of-fit measure \\
\hline$x^{2}$ & 211.722 \\
$p$-value & $<0.0001$ \\
d.f. & 103 \\
$x^{2} /$ d.f. & 2.050 \\
RMSEA & 0.080 \\
$p$-value for test of close fit & 0.050 \\
SRMR & 0.078 \\
NNFI & 0.950 \\
CFI & 0.940 \\
AGFI & 0.860 \\
\hline
\end{tabular}

Notes: AGFI, Adjusted Goodness of Fit index; CFI, Comparative Fit Index; d.f., degrees of freedom; NNFI, Non Normed Fit Index; RMSEA, Root Mean Square error of Approximation; SRMR, Standardized Root Mean Square Residual.

Table 5. Analysis of correlation among the PAAS-IT and its subscales, the PAAF, the TAS-20 and its subscales.

\begin{tabular}{lccc}
\hline & PAAS-IT sum & Fantasised baby & Anticipated baby \\
\hline PAAF & $.498^{* *}$ & $.504^{* *}$ & $.182^{*}$ \\
TAS-20 SUM & -.111 & -.125 & -.091 \\
TAS-20 F1 & -.116 & $-.207^{* *}$ & -.076 \\
TAS-20 F2 & -.034 & -.086 & -.016 \\
TAS-20 F3 & -.107 & .012 & -.122 \\
\hline
\end{tabular}

Notes: Pearson's $r$ correlation.

${ }^{*} p<.05 ;{ }^{* *} p<.001$; PAAS-IT, Paternal Antenatal Attachment Scale - Italian Translation.

Fantasised baby, Anticipated baby: subscales derived from factor analysis in the present study. PAAF, Paternal Antenatal Attitudes toward the Fetus. TAS-20: Toronto Alexithymia Scale; TAS-F1: difficulty identifying feelings; TAS-F2: difficulty describing feelings; TAS-F3: externally oriented thinking.

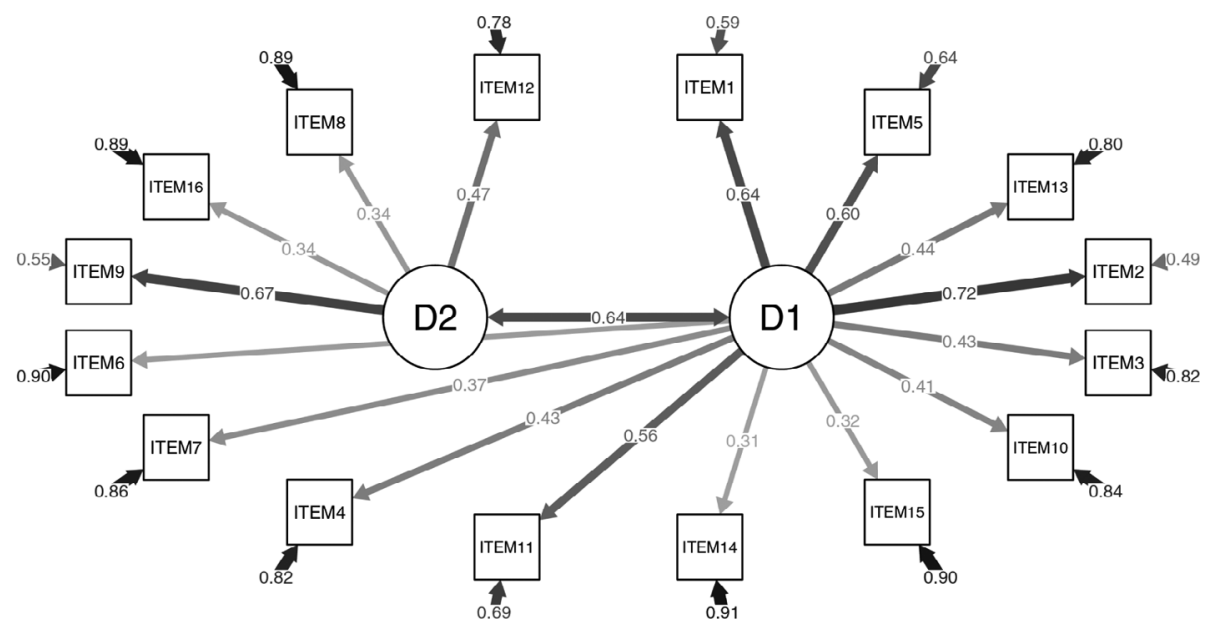

Figure 2. Path diagram with standardised structural coefficients of 16-item questionnaire. All coefficients in the model are statistically significant at a $p$-value of less than 0.05 . (ITEMS, D1 and D2 are in Table 4.)

consistency and split-half reliability of Italian administration were adequate. The mean score of the Global Attachment Score (PAAS-IT total) was higher compared to that of the original study (Condon, 1993), but similar to that found in a prospective study on first-time fathers 
(Condon et al., 2013). This result may be explained by the higher proportion of first-time fathers in the Italian study with respect to the original Australian sample, and related to the fact that men were enrolled into the study if their partner was in the third trimester of pregnancy and thus had already experienced quickening. The literature has demonstrated that antenatal attachment becomes more intense for women and men as the pregnancy progresses (Cannella, 2005; Habib \& Lancaster, 2006, 2010) and there is some evidence regarding prenatal attachment as being stronger towards the first child compared to subsequent children (Alhusen, 2008; Cannella, 2005; Ustunsoz et al., 2010; Yarcheski et al., 2009).

According to the factor structure suggested by Condon (1993), a two-factors solution was obtained through PCA and CFA that quantifies the relationship between items and the latent dimensions in a measurement model (Bagozzi \& Yi, 2012; Burro, 2016). In the PAAS-IT the items clustered in a different way compared to the original PAAS, suggesting that the Italian fathers' involvement with the unborn baby may differ from that of Australian fathers. Possibly there is a more complex attachment process in Italian men. Rather than it being characterised by the quality of the emotional experience towards the unborn baby, or the intensity of the time spent in attachment mode, the two dimensions of PAAS-IT seem to describe two different processes in the father's mind: one relating to fantasies, dreams and imagining the baby, the other one closer to a realistic evaluation of the baby's presence/ absence. The items clustering on the first factor, named Fantasising about the unborn baby, suggest the idea of a father picturing the fetus in his mind, dreaming about him or her, searching for an interaction with the imagined baby and feeling emotions towards the fetus (e.g. Frequent/infrequent picturing the fetus in imagination; Frequent/infrequent thoughts of the future child; Frequent/infrequent dreams about the baby; and Frequent/infrequent palpation of fetus). The items loading on the second factor, named Anticipating the real baby, recall the idea of a father facing the real existence of the unborn baby, giving a name to the baby, anticipating his first impressions of the baby, fearing the possible loss of the baby (e.g. Clear/vague ideas of the baby's names; Anticipate positive/negative his first impressions of baby; Sadness/mixed feelings towards a fantasised fetal loss). The items belonging to this factor seem to describe a father being able to differentiate his own fantasies, desires and mental projections from the fetus, increasingly recognising the baby as a separate person.

Clinically, the two dimensions of the PAAS-IT are consistent with the psychoanalytical framework of childbearing (Cramer \& Palacio-Espasa, 1993; Winnicott, 1958), recalling the relevant psychological processes and tasks that parents have to accomplish to bond with the fetus creating a representation of the unborn baby during pregnancy (the imagined baby), and to develop a sound bonding with their baby postnatally (the real baby).

However, it is important to note that, while the global scale of the PAAS-IT and its first factor Fantasising the unborn baby show good internal consistency, the second factor Anticipating the real baby has a poor alpha coefficient. A possible explanation is that the factor consists of only four items and it is known that Cronbach's alpha coefficient is affected by the number of items.

Therefore, although the scores of the two subscales can be calculated by summing up, it may be important to consider the clinical significance of the two factors in a qualitative way. The study results suggest relying more on the PAAS-IT total score to evaluate paternal antenatal attachment and to compare it in different populations.

In line with Condon's (1993) and Corkindale's (personal communication, 2004) results, the Italian sample also found that item 6 'Fetus as a little person/thing' loaded weakly on 
both factors, suggesting that the appreciation of the baby as a person is a somewhat complex process and perhaps should be also investigated qualitatively.

With regard to concurrent validity, the correlational analysis highlighted that the PAAS-IT scores were unrelated to the TAS-20, except for the subscale Anticipating the real baby (PAAS-IT) resulting in a modest negatively correlation with the subscale Difficulty identifying feelings (TAS-20). This result is consistent with the idea that the possibility of developing an antenatal emotional investment toward the baby is supposed to require a capacity to be in contact with one's own feelings and emotions. Accordingly, fathers scoring high in their capacity to represent the presence of the real baby seemed also more able to recognise their own feelings. Finally, in line with the expectations, the PAAS-IT correlated positively with the PAAF, which was a pool of questions specially created to measure the expectant father's attitudes towards his fetus, particularly the emotional involvement and the father's way of interacting with his unborn child. As both questionnaires investigate contents regarding paternal emotions and behaviours relating to a general feeling of love for the unborn baby, the robust correlation between their total scores seem to support the content validity of the Italian version of the instrument.

\section{Limitations}

The limitations in this study include the cross-sectional nature of the research design, the use of self-report instruments, the absence of the assessment of the quality of the marital relationship and the small sample size. Future studies assessing this construct in Italian fathers may address these limitations, in particular by expanding the sample size, to better explore the validity of the two factors found in the present study compared with those found in Condon's (1993) original study and in order to evaluate a short version of the questionnaire by means of an items reduction.

\section{Conclusion}

The results of the present study show that the Italian version of the PAAS has satisfactory psychometric characteristics and a sound factor structure. The way the items cluster onto the factors differs from the original study, suggesting cultural differences and a particular way of Italian fathers becoming emotionally involved with their unborn baby. With this caveat, it would perhaps be better to consider the global score of PAAS-IT as the indicator of the overall paternal antenatal attachment. The inspection of the two factors Fantasising about the unborn baby and Anticipating the real baby may contribute to a more qualitatively accurate and detailed picture of the particular features of the paternal antenatal attachment by which every man is different.

\section{Acknowledgements}

The authors would like to thank Prof. J. Condon for the permission to translate the instrument, Prof. P.L. Righetti, M.T. Dell'Avanzo for providing their previous Italian version, Prof. J. Smith and Prof. S. Matthey for their linguistic assistance in some sections. 


\section{Disclosure statement}

No potential conflict of interest was reported by the authors.

\section{Funding}

This research did not receive any grant from funding agencies in the public, commercial, or not-for-profit sectors.

\section{References}

Alhusen, J. L. (2008). A literature update on maternal-fetal attachment. Journal of Obstetric, Gynecologic, \& Neonatal Nursing, 37, 315-328. doi:10.1111/j.1552-6909.2008.00241.x

Bagby, R. M., Parker, J. D. A., \& Taylor, G. J. (1994). The twenty-item Toronto Alexithymia Scale - I. Item selection and cross-validation of the factor structure. Journal of Psychosomatic Research, 38, 23-32. doi:10.1016/0022-3999(94)90005-1

Bagozzi, R., \& Yi, Y. (2012). Specification, evaluation, and interpretation of structural equation models. Journal of the Academy of Marketing Science, 40, 8-34. doi:10.1007/s11747-011-0278-x

Beaton, D. E., Bombardier, C., Guillemin, F., \& Ferraz, M. B. (2000). Guidelines for the process of crosscultural adaptation of self-report measures. Spine, 25, 3186-3191. doi:10.1097/00007632-20001215000014

Bibring, G. L. (1959). Some considerations of the psychological processes in pregnancy. The Psychoanalytic Study of the Child, 16, 113-121.

Bowlby, J. (1969). Attachment and loss (Vol.1). New York, NY: Basic Books.

Boyle, G. J. (1985). Self-report measures of depression: Some psychometric considerations. British Journal of Clinical Psychology, 24, 45-59.

Brandon, A. R., Pitts, S., Denton, W. H., Stringer, C. A., \& Evans, H. M. (2009). A history of the theory of prenatal attachment. Journal of Prenatal \& Perinatal Psychology \& Health: Apppah, 23, 201-222.

Bressi, C., Taylor, G., Parker, J., Bressi, S., Brambilla, V., Aguglia, E., ... Todarello, O. (1996). Cross validation of the factor structure of the 20-item Toronto Alexithymia Scale: An Italian multicenter study. Journal of Psychosomatic Research, 41, 551-559. doi:10.1016/S0022-3999(96)00228-0

Bretherton, I. (1985). Attachment theory: Retrospect and prospect. Monographs of the Society for Research in Child Development, 50, 3-35.

Burro, R. (2016). To be objective in Experimental Phenomenology: A Psychophysics application. Springer Plus, 5, 1-15. doi:10.1186/s40064-016-3418-4

Cannella, B. L. (2005). Maternal-fetal attachment: An integrative review. Journal of Advanced Nursing, 50, 60-68. doi:10.1111/j.1365-2648.2004.03349.x

Cataudella, S. C., Lampis, J., Busonera, A., Marino, L., \& Zavattini, G. C. (2016). From parental-fetal attachment to a parent-infant relationship: A systematic review about prenatal protective and risk factors. Life Span and Disability, 19, 185-219.

de Cock, E. S., Henrichs, J., Vreeswijk, C. M., Maas, A. J., Rijk, C. H., \& van Bakel, H. J. (2016). Continuous feelings of love? The parental bond from pregnancy to toddlerhood. Journal of Family Psychology, 30, 125-134. doi:10.1037/fam0000138

Condon, J.T. (1985). The parental-foetal relationship-a comparison of male and female expectant parents. Journal of Psychosomatic Obstetrics \& Gynecology, 4, 271-284. doi:10.3109/01674828509016729

Condon, J.T. (1993). The assessment of antenatal emotional attachment: Development of a questionnaire instrument. British Journal of Medical Psychology, 66, 167-183. doi:10.1111/j.2044-8341.1993. tb01739.x

Condon, J., Corkindale, C., Boyce, P., \& Gamble, E. (2013). A longitudinal study of father-to-infant attachment: Antecedents and correlates. Journal of Reproductive and Infant Psychology, 31, 15-30. doi:10.1080/02646838.2012.757694 
Cramer, B., \& Palacio-Espasa, F. (1993). La pratique des psychothérapies mères-bébés: Études cliniques et techniques [The practice of mother-baby psychotherapies: Clinical and technical studies]. Paris: Presses Universitaires de France.

Cranley, M. S. (1981). Development of a tool for the measurement of maternal attachment during pregnancy. Nursing Research, 30, 281-284.

Della Vedova, A. M. (2005). The construct of "parental-fetal attachment": A review on the current knowledge. Imago, 12, 341-359.

Della Vedova, A. M. (2014). Maternal psychological state and infant's temperament at three months. Journal of Reproductive and Infant Psychology, 32, 520-534. doi:10.1080/02646838.2014.947472

Della Vedova, A. M., Dabrassi, F., \& Imbasciati, A. (2008). Assessing prenatal attachment in a sample of Italian women. Journal of Reproductive and Infant Psychology, 26, 86-98. doi:10.1080/02646830701805349

Deutsch, H. (1945). The psychology of women (Vol. II). New York, NY: Grune \& Stratton.

Habib, C., \& Lancaster, S. (2006). The transition to fatherhood: Identity and bonding in early pregnancy. Fathering, 4, 235-253.

Habib,C., \&Lancaster,S.(2010).Changes in identity and paternal-foetal attachmentacrossa first pregnancy. Journal of Reproductive and infant Psychology, 28, 128-142. doi:10.1080/02646830903298723

Horn, J. L. (1965). A rationale and test for the number of factors in factor analysis. Psychometrika, 30, $179-185$.

Kim, H. Y. (2013). Statistical notes for clinical researchers: Assessing normal distribution (2) using skewness and kurtosis. Restor Dent Endod, 38, 52-54. doi:10.5395/rde.2013.38.1.52

Kunkel, G. F. M., \& Doan, H. M. (2003). Fetal attachment and depression: Measurement matters. Journal of Prenatal \& Perinatal Psychology \& Health, 18, 149-166.

Laxton-Kane, M., \& Slade, P. (2002). The role of maternal prenatal attachment in a woman's experience of pregnancy and implications for the process of care. Journal of Reproductive and Infant Psychology, 20, 253-266. doi:10.1080/0264683021000033174

Muller, M. E. (1993). Development of the prenatal attachment inventory. Western Journal of Nursing Research, 15, 199-215.

Raimondo, M. (2000). The measurement of trust in marketing studies: A review of models and methodologies. Proceedings of the XVI IMP Conference, Bath (UK): University of Bath, 7-9. September.

Ramchandani, P. G., Domoney, J., Sethna, V., Psychogiou, L., Vlachos, H., \& Murray, L. (2013). Do early father-infant interactions predict the onset of externalising behaviours in young children? Findings from a longitudinal cohort study. Journal of Child Psychology and Psychiatry, 54, 56-64. doi:10.1111/ j.1469-7610.2012.02583.x

Revelle, W. (2016). Psych: Procedures for personality and psychological research. Evanston, Illinois, USA: Northwestern University. Retrieved from https://CRAN.R-project.org/package=psychVersion=1.6.12

Righetti, P. L., Dell'Avanzo, M., Grigio, M., \& Nicolini, U. (2005). Maternal/paternal antenatal attachment and fourth-dimensional ultrasound technique: A preliminary report. British Journal of Psychology, 96, 129-137. doi:10.1348/000712604X15518

Rosseel, Y. (2012). Lavaan: An R package for structural equation modeling. Journal of Statistical Software, 48, 1-36. Retrieved from http://www.jstatsoft.org/v48/i02/

R Core Team. (2016). R: A language and environment for statistical computing. Vienna, Austria: $\mathrm{R}$ Foundation for Statistical Computing. Retrieved from https://www.R-project.org/

Sameroff, A. J. (1999). Ecological perspectives on developmental risk. In J. D. Osofsky \& H. E. Fitzgerald (Eds.), WAIMH handbook of infant mental health: Vol. 4. Infant mental health groups at risk (pp. 223248). New York, NY: Wiley.

Schermelleh-Engel, K., Moosbrugger, H., \& Müller, H. (2003). Evaluating the fit of structural equation models: Tests of significance and descriptive goodness of-fit measures. Methods Psychol Res Online, 8, 23-74.

Seimyr, L., Sjögren, B., Welles-Nyström, B., \& Nissen, E. (2009). Antenatal maternal depressive mood and parental-fetal attachment at the end of pregnancy. Archives of Women's Mental Nealth, 12, 269-279. doi:10.1007/s00737-009-0079-0

Siddiqui, A., \& Hägglöf, B. (2000). Does maternal prenatal attachment predict postnatal mother-infant interaction? Early human development, 59, 13-25. 
Soulé, M. (1982). L'enfant dans la tête, l'enfant imaginaire [The baby in the mind, the imagined baby]. In T. B. Brazelton, B. Cramer, L. Kreisler, R. Schappi, \& M. Soulè (Eds.), La dinamique du nourisson [The newborn's dynamics] (pp. 135-175). Paris: Esf.

Stern, D. N. (1995). The motherhood constellation: A unified view of parent-infant psychotherapy. New York, NY: Basic Books.

Ustunsoz, A., Guvenc, G., Akyuz, A., \& Oflaz, F. (2010). Comparison of maternal-and paternal-fetal attachment in Turkish couples. Midwifery, 26, e1-e9. doi:10.1016/j.midw.2009.12.006

Van den Bergh, B., \& Simons, A. (2009). A review of scales to measure the mother-foetus relationship. Journal of Reproductive and Infant Psychology, 27, 114-126. doi:10.1080/02646830802007480

Walsh, J. (2010). Definitions matter: If maternal-fetal relationships are not attachment, what are they? Archives of Women's Mental Health, 13, 449-451. doi:10.1007/s00737-010-0152-8

Watkins, D. (1989). The role of confirmatory factor analysis in cross-cultural research. Int J Psychol, 24, 685-701.

Weaver, R. H., \& Cranley, M. S. (1983). An exploration of paternal-fetal attachment behavior. Nursing Research, 32, 68-72.

Winnicott, D. W. (1958). Collected works: From paediatrics to psycho-analysis. London: Tavistock.

Yarcheski, A., Mahon, N. E., Yarcheski, T. J., Hanks, M. M., \& Cannella, B. L. (2009). A meta-analytic study of predictors of maternal-fetal attachment. International Journal of Nursing Studies, 46, 708-715. doi:10.1016/j.ijnurstu.2008.10.013 


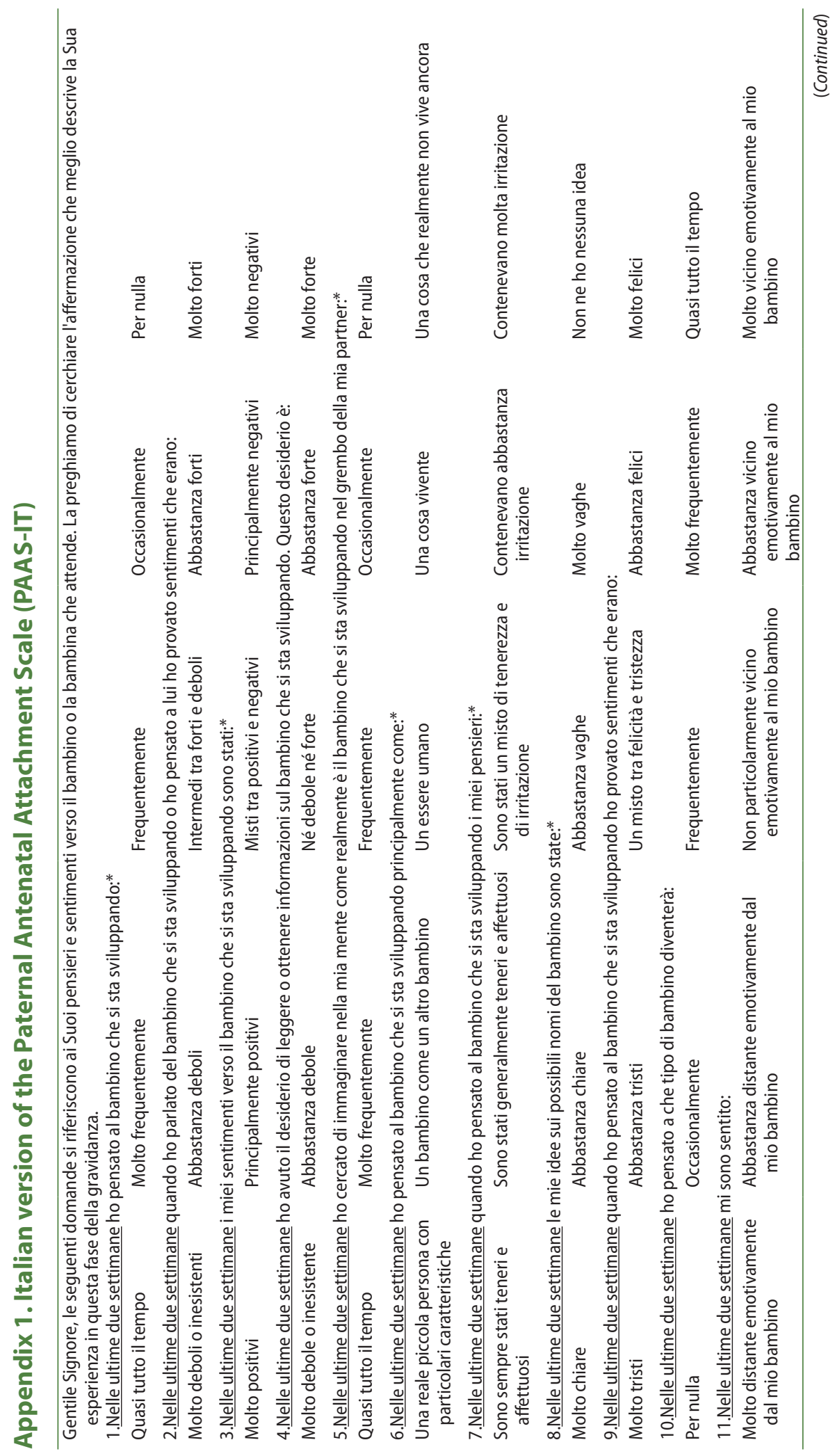




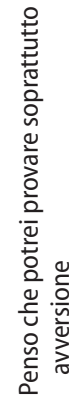

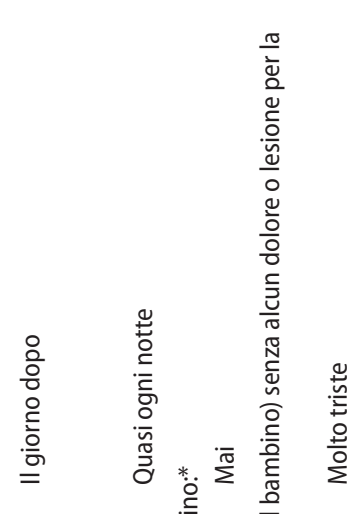

অัّ

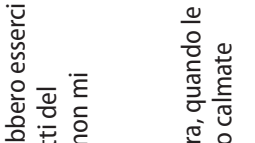

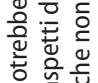

은 는 웅

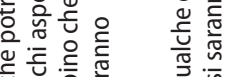

恼苋蛋

응

응 仓ัن

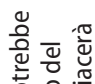

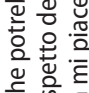

范总

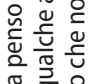

है을

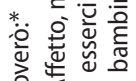

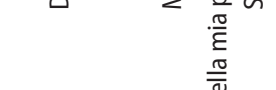

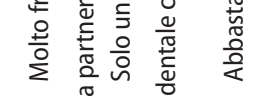

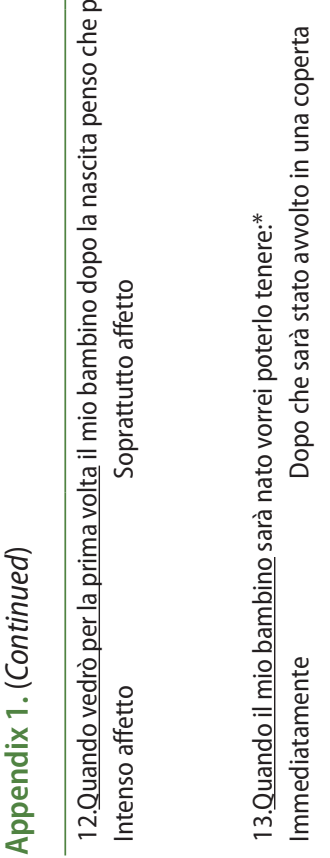

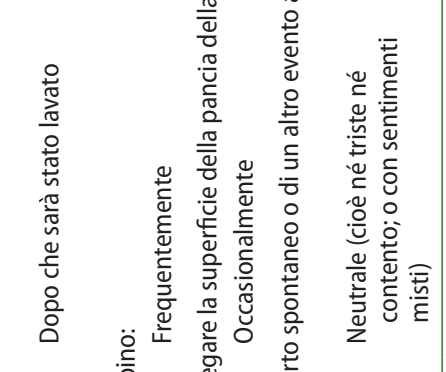

एक

浯

जू

离 $\quad$ 元

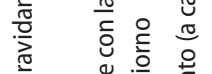

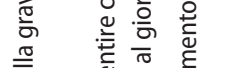

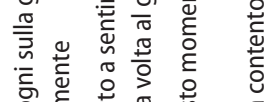

ปั๊

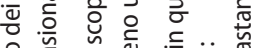

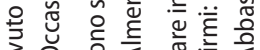

庵人

ป

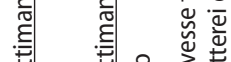

जัّ

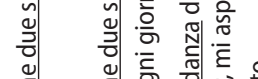

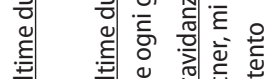

党

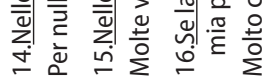

